\title{
Involvement of connexin 43 in meiotic maturation of bovine oocytes
}

\author{
C. Vozzi ${ }^{1}$, A. Formenton ${ }^{2}$, A. Chanson ${ }^{1}$, A. Senn ${ }^{1}$, R. Sahli ${ }^{3}$, \\ P. Shaw ${ }^{4}$, P. Nicod ${ }^{2}$, M. Germond ${ }^{1}$ and J-A. Haefliger ${ }^{2 *}$ \\ ${ }^{1}$ Reproductive Medicine Unit, Department of Obstetrics and Gynecology, \\ ${ }^{2}$ Department of Internal Medicine, ${ }^{3}$ Institute of Microbiology and ${ }^{4}$ Institute of Pathology, \\ CHUV-1011 Lausanne, Switzerland
}

In ovarian follicles, cumulus cells provide the oocyte with small molecules that permit growth and control maturation. These nutrients reach the germinal cell through gap junction channels, which are present between the cumulus cells and the oocyte, and between the cumulus cells. In this study the involvement of intercellular communication mediated by gap junction channels on oocyte maturation of in vitro cultured bovine cumulus-oocyte complexes (COCs) was investigated. The stages of oocyte maturation were determined by Hoechst 33342 staining, which showed that $90 \%$ of COCs placed in the maturation medium for $24 \mathrm{~h}$ progress to the metaphase II stage. Bovine COC gap junction communication was disrupted initially using $n$ alkanols, which inhibit any passage through gap junctions. In the presence of 1 -heptanol $\left(3 \mathrm{mmol} \mathrm{I}^{-1}\right)$ or octanol ( $3.0 \mathrm{mmol} \mathrm{I}^{-1}$ and $0.3 \mathrm{mmol} \mathrm{I}^{-1}$ ), only $29 \%$ of the COCs reached metaphase II. Removal of the uncoupling agent was associated with restoration of oocyte maturation, indicating that treatment with $n$-alkanols was neither

\section{Introduction}

In ovarian follicles, cumulus cells play an important role in oocyte growth and differentiation by providing the germinal cell with nutrients and by controlling both nuclear and cytoplasmic maturation when oocytes are selected for ovulation (Eppig, 1996). In response to gonadotrophin in vivo, the fully grown immature oocytes resume maturation and undergo germinal vesicle breakdown (GVBD), progressing from prophase of the first meiotic division to metaphase II (Dekel and Beers, 1980). Several layers of tightly adherent cumulus cells surround the immature mammalian oocytes. There is a complex interplay between oocytes and cumulus cells during folliculogenesis (Buccione et al., 1990; Gougeon, 1996) that is mediated by growth factors and hormones. Cumulus cells communicate through an intricate network of transmembrane channels called gap junctions (Grazul-Bilska et al., 1997); the innermost layer of

*Correspondence

Email: jhaeflig@chuv.hospvd.ch cytotoxic nor irreversible. Concentrations of connexin 43 (Cx43), the major gap junction protein expressed in the COCs, were decreased specifically using a recombinant adenovirus expressing the antisense Cx43 cDNA (Adas $\mathrm{Cx} 43$ ). The efficacy of adenoviral infection was $>95 \%$ in cumulus cells evaluated after infection with recombinant adenoviruses expressing the green fluorescence protein. RT-PCR performed on total RNA isolated from Ad-asCx43infected COCs showed that the rat Cx43 cDNA was transcribed. Western blot analysis revealed a three-fold decrease in Cx43 expression in COCs expressing the antisense RNA for Cx43. Injection of cumulus cells with Lucifer yellow demonstrated further that the resulting lower amount of Cx43 in infected COCs is associated with a twofold decrease in the extent of coupling between cumulus cells. In addition, oocyte maturation was decreased by $\mathbf{5 0} \%$ in the infected COC cultures. These results indicate that Cx43-mediated communication between cumulus cells plays a crucial role in maturation of bovine oocytes. cumulus cells extends cytoplasmic processes through the zona pellucida, a thick extracellular matrix, forming gap junctions with the oocyte (White and Paul, 1999). These junctional complexes, composed of proteins belonging to the connexin family (Bruzzone et al., 1996; Kumar and Gilula, 1996), mediate the exchange of ions and metabolites (up to $1 \mathrm{kDa}$ ) between neighbouring cells (Goodenough et al., 1996).

Simon et al. (1997) demonstrated that connexin 37 (Cx37) is present in gap junctions between the oocyte and the cumulus cells, and that $\mathrm{Cx} 37$-deficient mice lack mature follicles, fail to ovulate and develop inappropriate corpora lutea. In Cx37 knockout mice, cumulus-oocyte cell coupling is ablated, although cumulus-cumulus cell coupling persists (White and Paul, 1999). The junctions joining the cumulus cells are formed primarily of Cx43 (Beyer et al., 1989) and during in vitro culture, transfer of Lucifer yellow between cumulus cells still occurs after a $24 \mathrm{~h}$ period (Sutovsky et al., 1993).

Oocytes lack many transport systems for nutrient uptake (nucleotides, amino acids and sugars) and, in rodent 
species, gap junction transfer of nutrients from cumulus cells to the oocyte is required for oocyte growth (Eppig, 1996), whereas transfer of CAMP inhibits oocyte maturation (Dekel, 1988; Granot and Dekel, 1997). In cows, the effects of cAMP on oocyte cell cycle regulation are not established as clearly as in mice; meiotic inhibition in bovine oocytes is the result of co-operation among cumulus, granulosa and theca cells (Richard and Sirard, 1996a,b; Richard et al., 1997). The function of cumulus cells may be more complex than the simple transmission of cAMP inhibition signals. These cells may also transmit a positive signal leading to meiotic resumption, which can reverse the inhibitory signal by stimulating the cumulus to produce a GVBD-inducing factor (Sirard and Bilodeau, 1990a,b). In pig ovaries, Cx43 was localized to the granulosa cells of the developing follicle and it was demonstrated that gonadotrophin stimulation enhances the intensity of immunoreactive Cx43 (Lenhart et al., 1998). Metabolic coupling experiments have shown that the coupling between cumulus cells and the oocyte persists at the time of meiotic resumption by oocytes (Heller and Schultz, 1980; Eppig, 1982; Bornslaeger and Schultz, 1985; Larsen et al., 1986; de Loos et al., 1991; Laurincik et al., 1992). Therefore, the integrity of the gap junctional network could be necessary for induction of meiotic maturation of oocytes.

In the present study, the physiological role played by the gap junction network in meiotic maturation of oocytes in vitro was investigated. All gap junction communication was first blocked by exposing bovine COCs to several alkanols known as gap junction uncouplers (Christ, 1995; Largo et al., 1997; Chanson et al., 1998; Venance et al., 1998). In a second series of experiments, Cx43 expression was disrupted specifically by infecting the COCs with a recombinant adenovirus expressing a Cx43 antisense RNA.

\section{Materials and Methods}

\section{Recovery of the cumulus-oocyte complexes}

Cow ovaries were obtained from the local abattoir. Immediately after collection, the ovaries were placed into sterile PBS supplemented with $50 \mu \mathrm{g}$ gentamycin $\mathrm{ml}^{-1}$ and maintained at $39^{\circ} \mathrm{C}$ in a waterbath. The ovaries were transported to the laboratory within $1-2 \mathrm{~h}$ in an isotherm box maintained at about $35-39^{\circ} \mathrm{C}$ and washed in sterile PBS with gentamycin. The follicular fluids were aspirated gently from small antral follicles $(2-8 \mathrm{~mm}$ in diameter) with a needle (19G) and a syringe $(5 \mathrm{ml})$. The sedimented COCs were transferred into $2 \mathrm{ml}$ Hepes-buffered medium 199 (M199-Hepes; Gibco BRL, Basel), supplemented with 10\% synthetic serum substitute (SSS; Irvine Scientific, San Francisco, CA) and $50 \mu$ g gentamicin $\mathrm{ml}^{-1}$, and adjusted to a final osmolarity of $290 \pm 2 \mathrm{mOsmol}^{-1}$. All the COCs were recovered under a stereomicroscope and rinsed several times with M199-Hepes. The COCs were pooled in two groups (A and B) following the morphological criteria of Blondin and Sirard (1995) and Chanson et al. (2001). COCs from group B were discarded.

\section{Maturation medium and $\mathrm{n}$-alkanols}

Oocyte meiotic maturation was carried out in a bicarbonated M199 medium (M199- $-\mathrm{HCO}_{3}$; Gibco BRL) adjusted to a final osmolarity of $290 \pm 2 \mathrm{mOsmol} \mathrm{I}^{-1}$ and supplemented with $10 \%$ SSS containing $84 \%$ human serum albumin, $16 \% \alpha$ - and $\beta$-globulins, $<1 \% \gamma$-globulins (Weathersbee et al., 1995; Tucker et al., 1996), 1 iu recombinant FSH ml-1 (Gonal F; Serono, Geneva), 1 iu LH $\mathrm{ml}^{-1}$ (LHADI; Serono) and $1 \mu \mathrm{g}$ oestradiol $\mathrm{ml}^{-1}$ (Sigma Chemical Co., St Louis, MO), in the presence or absence of standard concentrations of $n$-alkanols $(3 \mathrm{mmol} 1$-heptanol $\mathrm{I}^{-1} ; 3.0$ or $0.3 \mathrm{mmol}$ octanol $\mathrm{l}^{-1}$ ) (Christ, 1995; Largo et al., 1997; Chanson et al., 1998; Venance et al., 1998). The COCs (20 per well) were placed in $0.5 \mathrm{ml}$ medium. In vitro maturation was carried out by culturing the COCs for $22-24 \mathrm{~h}$ under standard incubation conditions $\left(39^{\circ} \mathrm{C}, 5 \%\right.$ $\mathrm{CO}_{2}$ and $95 \%$ air) in a humidified incubator (BB 16; Heraeus, Hanau). Each experimental replicate consisted of approximately 80 COCs retrieved from about 20 ovaries. The COCs were incubated in the culture medium with and without $3 \mathrm{mmol} 1$-heptanol $\mathrm{I}^{-1}$ to measure the reversibility of the effects of 1 -heptanol. After $24 \mathrm{~h}$ of culture, about $50 \%$ of the COCs of each group were processed to analyse their stage of maturation. The remaining $50 \%$ of each group were washed several times in the culture medium to remove 1-heptanol. The COCs were cultured for $24 \mathrm{~h}$ in the control medium. The index of maturation used in the present study was GVBD; to determine the maturational stage of the oocytes after $24 \pm 1 \mathrm{~h}$ or $48 \pm 1 \mathrm{~h}$ of culture, the oocytes were denuded in the presence of 80 iu hyaluronidase $\mathrm{ml}^{-1}$ (vortexed for $10 \mathrm{~min}$ ). The DNA of the germinal cells was stained with Hoechst $33342\left(10 \mu \mathrm{g} \mathrm{ml}^{-1}\right.$ in PBS) and visualized on an inverted fluorescence microscope. The presence of two fluorescent spots was indicative of metaphase II stage; when only one spot was detected the oocytes were considered to be in the germinal vesicle stage.

\section{Generation of recombinant adenoviruses}

Recombinant adenoviruses comprising the complete cDNA of rat Cx43 (Beyer et al., 1987) in the antisense orientation were constructed and fused (Ad-asCx43-GFP) or not $(\mathrm{Ad}-\mathrm{asC} \mathrm{C} 43)$ to the green fluorescent protein (GFP) cDNA to inhibit $\mathrm{Cx} 43$ expression. Adenovirus that expresses GFP only was used as a control. The GFP coding region was ligated into $\mathrm{pClneo}$ ( $\mathrm{pClneo-GFP)}$ to generate the Ad-GFP virus. The cassette of pCIneo-GFP encompassing the cytomegalovirus (CMV) promoter, the artificial intron of pCIneo, the coding region of GFP and the poly A addition signal of pClneo was inserted into pXC15-18 (Schaack et al., 1995) to produce the adenoviral transfer vector $p X C$ GFP. Ad-GFP was generated by homologous recombination in 293 cells after co-transfection by the calcium phosphate procedure of pJM17 (Hitt et al., 1998) and pXC-eGFP. Viruses collected at day 10 after transfection were plaquepurified three times on HR911 cells (IntroGene, Leiden). Plaque assays were performed in six-well dishes with 30\% 
$(v / v)$ confluent HR911 cells. Cells were infected with $400 \mu \mathrm{l}$ virus suspension in Dulbecco's modified Eagle's medium (DMEM) containing 10\% fetal calf serum (FCS), $250 \mathrm{U}$ penicillin $\mathrm{ml}^{-1}$ (Gibco BRL) and $250 \mu \mathrm{g}$ streptomycin $\mathrm{ml}^{-1}$ (Gibco BRL) for $1 \mathrm{~h}$, at which time the inoculum was replaced by $2.5 \mathrm{ml}$ per well of freshly prepared overlay equilibrated at $40^{\circ} \mathrm{C}$. The overlay contained $2 \times$ minimal essential medium (a five-fold dilution of $10 \times$ MEM; Life Technologies, Paisley), 20\% FCS and 2.5\% (w/v) Seaplaque agarose (FMC; Bioconcept, Allschwill). After the agarose solidified, the dishes were returned to the $\mathrm{CO}_{2}$ incubator and the plaques were scored at day 5 after infection. Viruses from three independent plaques were analysed by restriction enzyme digestion of viral DNA purified from 293 cells by the Hirt procedure (Hirt, 1967). Large stock viruses were purified by two rounds of caesium chloride centrifugation. The virus band $(1.5 \mathrm{ml})$ was collected and dialysed at $4^{\circ} \mathrm{C}$ against $10 \mathrm{mmol}$ Hepes $\mathrm{I}^{-1}, \mathrm{pH} 8.0,150 \mathrm{mmol} \mathrm{NaCl}$ $\mathrm{I}^{-1}$ in a Slide-A-Lyzer $(0.5-3.0 \mathrm{ml}$ capacity), gammairradiated $10 \mathrm{~K}$ dialysis cassette (Pierce, Rockford, IL). The adenovirus is an E1-E3 deleted, replication defective, recombinant human adenovirus type 5 allowing expression of GFP or the Cx43 antisense RNA or both under the control of the strong immediate early CMV promoter. COCs were incubated in the maturation medium with recombinant adenoviruses at approximately 50-100 virus particles per COC for $24 \mathrm{~h}$.

\section{RT-PCR amplification}

COCs $(n=35)$ frozen in liquid nitrogen were homogenized in $4 \mathrm{~mol}$ guanidium isothiocyanate buffer $\mathrm{I}^{-1}$, containing 25 mmol sodium citrate $\mathrm{I}^{-1}$ and $100 \mathrm{mmol} \beta$ mercaptoethanol $\mathrm{I}^{-1}$. Total RNA from COCs, either infected or uninfected, was extracted by the acid guanidiumisothiocyanate method (Chomczynski and Sacchi, 1987) and yields were evaluated by measuring absorbance at $260 \mathrm{~nm}$. Total RNA was treated for $30 \mathrm{~min}$ in the presence of $20 \mathrm{U}$ DNase I (Pharmacia, Dubendorf). Aliquots ( $1 \mu \mathrm{l})$ of DNase-treated RNA were reverse-transcribed as described by Haefliger et al. (2000).

The reverse-transcribed products were used for PCR reaction using Taq DNA polymerase (Gibco BRL) in the presence of $20 \mathrm{ng}$ sense primer and $20 \mathrm{ng}$ antisense primer (MWG-Biotech, München). The sense primer 5' TCTACGTCTTCTTCAAAGGCG $3^{\prime}$ sequence is located in the rat CX43 sequence; the other primer 5' AGTCAGTGCTTCTGACACA $3^{\prime}$ originated in front of the intron sequence of the viral DNA. These primers amplified a fragment of $657 \mathrm{bp}$. As positive controls, samples of viral DNA prepared by overnight digestion of purified virus particles were subjected to PCR amplification. The amplified DNA was visualized after ethidium bromide staining on an agarose gel.

\section{Western blot analysis}

Infected COCs or control COCs were homogenized in $100 \mathrm{mmol}$ Tris- $\mathrm{HCl} \mathrm{I-1,} \mathrm{pH} 7.4$, supplemented with
20 mmol EDTA $~^{-1}, 1 \mu \mathrm{g}$ pepstatin $\mathrm{A} \mathrm{ml}^{-1}, 1 \mu \mathrm{g}$ antipain $\mathrm{ml}^{-1}$ (all Merck, Dietikon), 1 mmol benzamidine ${ }^{-1}, 40$ kallikrein inactivator units (KIU) aprotinin $\mathrm{ml}^{-1}$ (Bayer, Zurich), $2 \mathrm{mmol}$ phenylmethylsulphonyl fluoride $\mathrm{I}^{-1}$ (PMSF; Sigma Chemical Co.) and $1 \mathrm{mmol}$ diisopropyl fluorophosphate $\mathrm{I}^{-1}$ (DFP; Aldrich Chemical Co., Milwaukee, WI). The homogenates were passed through a needle to shear the DNA and centrifuged at $3000 \mathrm{~g}$ for $10 \mathrm{~min}$ to pellet intact cells. Supernatants were collected and centrifuged for $60 \mathrm{~min}$ at $100000 \mathrm{~g}$ at $4^{\circ} \mathrm{C}$. The crude membrane preparation was pelleted and resuspended in a solubilization buffer containing $62.5 \mathrm{mmol}^{-1}$ Tris $\mathrm{I}^{-1}, \mathrm{pH}$ 8.0, 5\% (w/v) SDS and $10 \mathrm{mmol}$ EDTA ${ }^{-1}$. Samples of crude membrane preparation were fractionated by electrophoresis in a $12.5 \%(\mathrm{w} / \mathrm{v})$ polyacrylamide gel and immunoblotted onto Immobilon PVDF membranes (Millipore Co., Volketswil). The membrane was stained with Ponceau S solution (Sigma, Steinheim) and incubated for $4 \mathrm{~h}$ with a monoclonal antibody against Cx43 (Zymed laboratories Inc., San Francisco, CA) diluted 1:10 000 in blocking buffer. For quantification, the lanes were cut longitudinally in two parts. One part was incubated for $4 \mathrm{~h}$ with a monoclonal antibody against $\mathrm{C} \times 43$ (Zymed laboratories Inc.) diluted 1:10000 in blocking buffer (Haefliger et al., 1997, 1999) and the other part was incubated with a monoclonal antibody against $\alpha$-tubulin (T5168; Sigma) diluted 1:10000 in blocking buffer. After repeated rinsing in PBS and PBS $+0.1 \%(\mathrm{v} / \mathrm{v})$ Tween 20, immunoblots were incubated overnight at $4^{\circ} \mathrm{C}$ with an antimouse IgG antibody coupled with alkaline phosphatase (Dako Diagnostic AG, Zug) diluted 1:5000. The bands were developed with BCIP-NBT method (AP development reagent; BioRad Laboratories, Glattburg).

\section{Lucifer yellow microinjection}

Intercellular communication between the cumulus complex cells was assessed by Lucifer yellow microinjection. The oocyte of the COCs was held with a micropipette and an individual cell was impaled within each COC with a glass microelectrode filled with a $4 \%(\mathrm{v} / \mathrm{v})$ Lucifer yellow $\mathrm{CH}$ (Sigma Chemical Co.) solution in $3 \mathrm{mmol}$ lithium chloride $\mathrm{I}^{-1}$ buffered to $\mathrm{pH} 7.2$ with 10 mmol Hepes $\mathrm{I}^{-1}$. The tracer was pressure-injected into the cell for $30 \mathrm{~s}$. The injections were carried out on an epifluorescenceequipped inverted microscope (IMT2; Olympus, Zürich) with Hofman contrast and a heated stage at $37^{\circ} \mathrm{C}$. Colour slides of the microinjected COCs were projected and the extent of dye coupling was evaluated by counting the number of Lucifer yellow-labelled cells within each COC.

\section{Statistical analysis}

Densitometric analysis of immunolabelled proteins (western blot analysis) was performed using a Molecular Dynamics scanner (Sunnyvale), which integrates areas and corrects for background. Signals for Cx43 were related to the corresponding tubulin signals. Relative protein concentrations calculated from western blot analysis and the extent 
of dye diffusion were compared using superANOVA and Scheffe's test. Data are expressed as mean \pm SEM. Statistical significance was defined at values of $P<0.05$ and $P<0.01$. The statistical analysis of oocyte meiotic maturation was performed using a contingency table (StatView for Macintosh).

\section{Results}

\section{Effects of n-alkanols on meiotic maturation of oocytes}

Freshly collected oocytes were immature at the beginning of the culture period, as indicated by Hoechst staining of denuded oocytes, which demonstrated that all oocytes were in the germinal vesicle stage. After $24 \mathrm{~h}$ in the maturation medium, $85 \%$ (28 of 33) of the oocytes present in COCs resumed meiosis and were recovered in the metaphase II stage. In contrast, only 53\% (49 of 92) of the oocytes matured when denuded before in vitro culture, indicating that cumulus cells play a role in oocyte maturation.

Two gap junction uncoupling agents (1-heptanol and octanol) were added to the maturation medium for $24 \mathrm{~h}$ to investigate the involvement of gap junctions in meiotic maturation of oocytes. Cumulus cell expansion and morphology of oocytes cultured in the medium with heptanol were similar to those of control COCs matured without heptanol or octanol. In the presence of 3.0 or $0.3 \mathrm{mmol}$ octanol $\mathrm{I}^{-1}, 77.6 \%$ of the oocytes were blocked at the germinal vesicle stage ( $n=74$ oocytes in total), whereas $98.6 \%$ of the control oocytes ( $n=76$ oocytes in total) resumed meiosis in maturation medium (Fig. 1a). When 3 mmol 1-heptanol $\mathrm{I}^{-1}$ was added to the culture medium ( $n=115$ oocytes in total) only $29 \%$ of the oocytes matured to the metaphase II stage, whereas $50 \%$ of the oocytes remained in the germinal vesicle stage and $21 \%$ matured to an intermediate stage (Fig. 1b). In the same experiment, $90 \%$ of control oocytes ( $n=93$ oocytes in total) were recovered in metaphase II stage, $4 \%$ remained in the germinal vesicle stage and $6 \%$ were recovered at an intermediate stage of maturation (Fig. 1b). The reversibility of 1-heptanol inhibition of maturation was studied further. After $24 \mathrm{~h}$ in the presence of 1-heptanol, only $28 \%$ of treated oocytes ( $n=79$ oocytes in total) resumed meiosis, whereas $88 \%$ of control oocytes ( $n=74$ oocytes in total) were recovered in metaphase II stage (Fig. 1c). Half of the oocytes incubated initially for $24 \mathrm{~h}$ in the presence of heptanol were incubated for a further $24 \mathrm{~h}$ in the absence of 1-heptanol. Removal of the uncoupling agent was associated with restoration of meiotic maturation of oocytes, as $63 \%$ of the oocytes ( $n=86$ oocytes in total) resumed meiosis, whereas $78 \%$ of control oocytes ( $n=60$ oocytes in total), which had not been incubated in the presence of heptanol, had resumed meiosis at $48 \mathrm{~h}$ (Fig. 1c).

\section{Effects of a decrease in Cx43 in cumulus cells on meiotic maturation of oocytes}

RT-PCR on RNA extracted from COCs infected during $24 \mathrm{~h}$ with $\mathrm{Ad}$-asCx43 (Fig. 2a) and Ad-asCx43-GFP (data not shown) demonstrated that antisense Cx43 RNA was transcribed $24 \mathrm{~h}$ after infection. The efficacy of infection was $>95 \%$, as evaluated by measuring the number of GFP fluorescent-positive cells in cumulus cells using $\mathrm{Ad}$ asCx43-GFP or Ad-GFP (Fig. 2b).

A kinetic study after adenovirus infection showed that the antisense Cx43 RNA was already detectable in COCs at $2 \mathrm{~h}$ after infection and that maximum expression was achieved $4 \mathrm{~h}$ after infection (Fig. 2c) and remained stable during the next $24 \mathrm{~h}$ of infection. Western blot analysis of proteins extracted from COCs was performed to determine whether the presence of an antisense Cx43 RNA affected the expression of Cx43 (Fig. 2d). Total proteins extracted from heart and aorta were used as positive controls. The extracts from aorta contained one major immunoreactive band (43 kDa), whereas the heart Cx43 was immunodetectable as three bands of 43-45 kDa (Haefliger et al., 1999). A reduction of $C x 43$ content in COCs was already detectable $6 \mathrm{~h}$ after infection (Fig. 2d). Quantitative evaluation of the Cx43 expressed in COCs was performed $24 \mathrm{~h}$ after infection (Fig. 3). The nylon membrane lanes were cut longitudinally in two parts for this purpose. One part was incubated with Cx43 antibodies and the other part was incubated with tubulin antibodies. Statistical analysis showed that Cx43 content was significantly decreased (Fig. 3) in COCs infected for $24 \mathrm{~h}$ with $\mathrm{Ad}-\mathrm{asCx} 43(n=4$; $P<0.01)$ compared with tubulin signals. Cumulus cell coupling was studied by Lucifer yellow injections at $24 \mathrm{~h}$ after infection to determine whether a decrease in Cx43 was associated with a decrease in cell-cell communication. One cumulus cell in each COC, located peripherally, was injected with Lucifer yellow; the coupling between cumulus cells infected with Ad-asCx43 was reduced by $66 \%$ compared with cumulus cells of uninfected COCs (Fig. 4). No diffusion of Lucifer yellow was detected between the injected cumulus cell and the oocyte, and addition of heptanol to COCs blocked all transfer of Lucifer yellow (data not shown).

After $24 \mathrm{~h}$ of culture, $91 \%$ of oocytes $(n=67)$ from control COCs had matured to the metaphase II stage. Furthermore, $89 \% \quad(n=96)$ of the oocytes from COCs infected with the Ad-GFP were recovered in the metaphase II stage, indicating that viral infection had no cytotoxic effect on meiotic maturation of oocytes. In contrast, only $48 \%(n=94$ oocytes in total) and 51\% ( $n=93$ oocytes in total) of oocytes present in COCs infected with either AdasCx43 or Ad-asCx43-GFP, respectively, underwent GVBD (Fig. 5).

\section{Discussion}

A semi-defined medium for in vitro maturation of immature bovine COCs has been developed to study the importance of gap junctions in meiotic maturation of bovine oocytes (Weathersbee et al., 1995; Tucker et al., 1996; Chanson et al., 2001). Bovine oocytes removed from small antral follicles were shown to have full meiotic competence after 

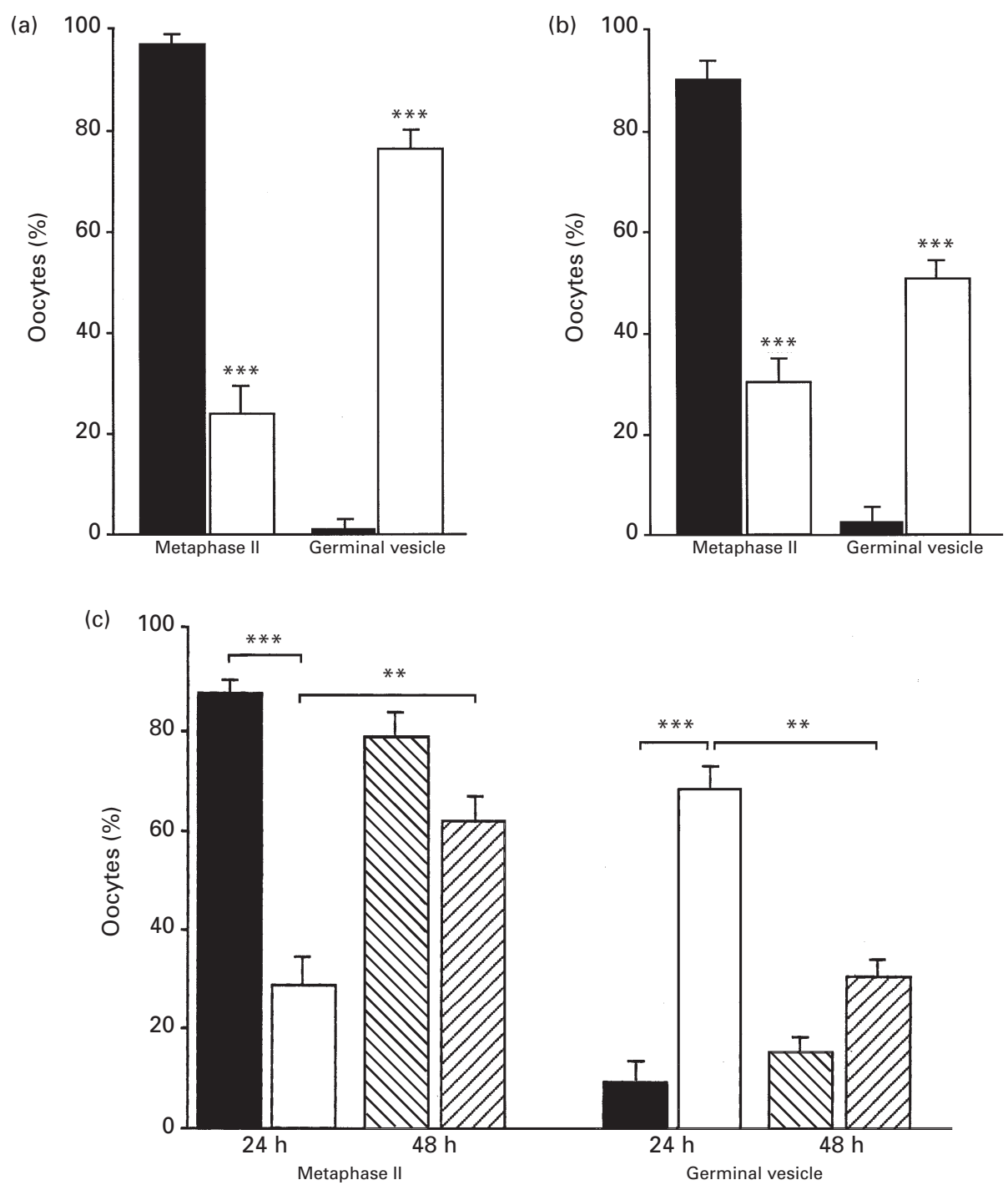

Fig. 1. Effect of $n$-alkanols on in vitro maturation of bovine oocytes. (a) Meiotic maturation of cumulus-oocyte complexes (COCs) incubated for $24 \mathrm{~h}$ in maturation medium in the presence of octanol $\left(0.3 \mathrm{mmol} \mathrm{I}^{-1}\right)$. A total of $77.6 \%$ of the treated oocytes $(\square ; n=74$ in total) were blocked at the germinal vesicle stage, whereas only $1.4 \%$ of control COCs $(\boldsymbol{\square} ; n=76$ in total) did not mature and $21 \%$ matured to an intermediate or intermediate stage (anaphase I or metaphase I, data not shown). Data are expressed as mean $\pm \operatorname{SEM}(n=3$ independent experiments). (b) In the presence of $3 \mathrm{mmol}^{1-h e p t a n o l} \mathrm{I}^{-1}$ in the culture medium $(\square ; n=115$ in total) only $29 \%$ of the treated oocytes matured to the metaphase II stage, whereas $50 \%$ of the oocytes remained in the germinal vesicle stage and $21 \%$ matured to an intermediate stage (data not shown). Ninety per cent of control COCs $(\boldsymbol{\square} ; n=93$ in total) were recovered in metaphase II stage, $4 \%$ remained in the germinal vesicle stage and $6 \%$ were recovered at an intermediate stage of maturation. Data are expressed as mean $\pm \operatorname{SEM}(n=5$ independent experiments). (c) The reversibility of the inhibitory effect of 1 -heptanol $\left(3 \mathrm{mmol} \mathrm{l}^{-1}\right)$ on maturation was studied. After $24 \mathrm{~h}$ in the presence of 1 -heptanol, only $28 \%$ ( $\square ; n=79$ in total) of treated oocytes were in metaphase II, whereas $88 \%$ of oocytes of control COCs had resumed meiosis ( $\boldsymbol{\square} ; n=74$ in total). Half of the COCs incubated for $24 \mathrm{~h}$ in the presence of heptanol were incubated for a further $24 \mathrm{~h}$ in the absence of 1-heptanol. In these conditions, $63 \%$ ( $\square ; n=86$ in total) of treated oocytes were recovered in the metaphase II stage, whereas $78 \%$ of oocytes of control COCs $(\triangle \nabla ; n=60$ in total) which had never been incubated in the presence of heptanol, had resumed meiosis after $48 \mathrm{~h}$. Data are expressed as mean \pm SEM ( $n=4$ independent experiments). ${ }^{* * *} P<0.001$ and ${ }^{* *} P<0.01$. 
(a)

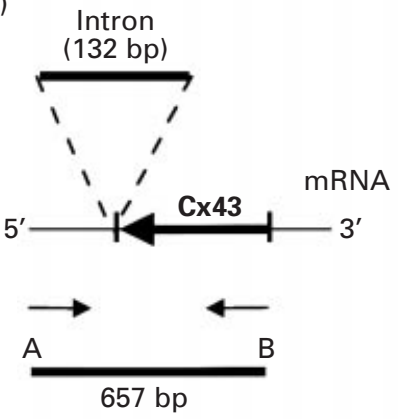

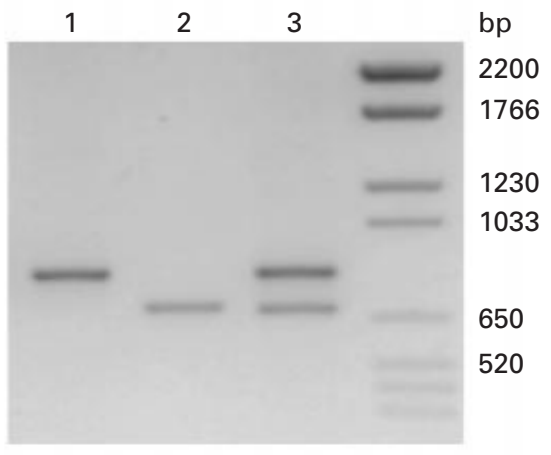

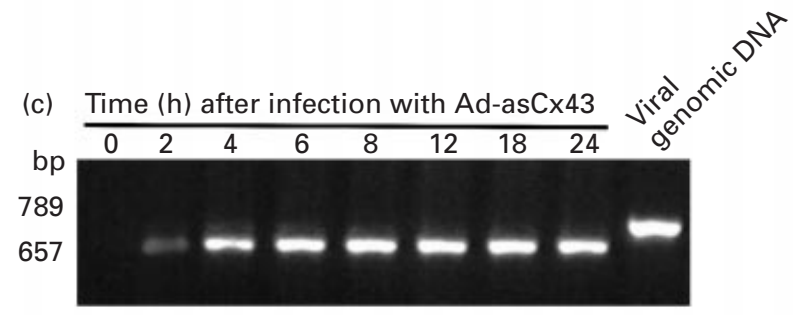

(b)
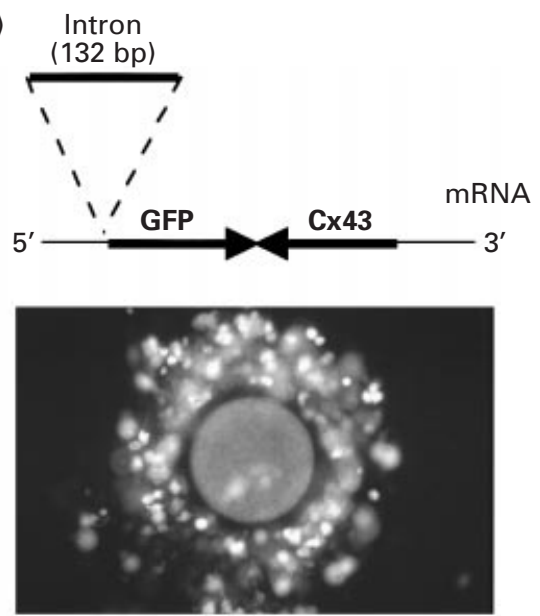

(d) Time (h) after infection with Ad-asCx43

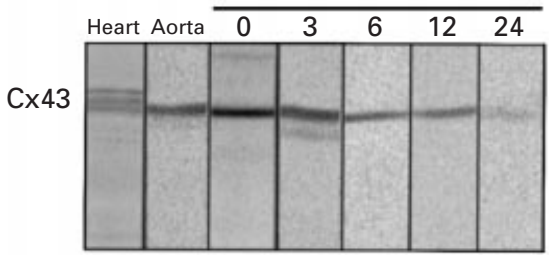

Fig. 2. Ad-asCx43-transcribed connexin 43 (Cx43) antisense RNA in bovine cumulus-oocyte complexes (COCs). (a) Schematic diagram depicting the RT-PCR strategy with the localization of the primers A and B. RT-PCR was performed using two oligonucleotides flanking the intron of $132 \mathrm{bp}$ to differentiate between the viral DNA and the RNA transcribed from the viral DNA. Total RNA was isolated from Ad-asCx43-infected COCs. PCR or RT-PCR products were size-fractionated on an agarose gel and stained with ethidium bromide. Lane 1: PCR amplified product of viral Ad-asCx43 genomic DNA extracted from Ad-asCx43; a single 789 bp product was amplified. Lane 2: RT-PCR product amplified from RNA extracted from bovine COCs infected with Ad-asCx43; a single 657 bp product was amplified. The sequence of 132 bp corresponding to the intron size was removed. Lane 3: PCR and RT-PCR products together to visualize the 132 bp difference. No band was amplified from RNA extracted from non-infected COCs (data not shown). (b) Schematic diagram depicting the construct allowing for the expression of the green fluorescent protein (GFP) and the antisense Cx43. After $24 \mathrm{~h}$ of infection, the efficacy of infection was $>95 \%$ as evaluated by GFP fluorescence in cumulus cells using Ad-asCx43-GFP or Ad-GFP. (c) Reverse-transcribed RNA extracted from non-infected COCs (time $=0 \mathrm{~h}$ ) or COCs infected with Ad-asCx43 at different times after infection was amplified by PCR using specific primers. A single 657 bp product was amplified. Antisense Cx43 transcripts were detected after $2 \mathrm{~h}$ of infection. This product was not observed in samples that were not reverse transcribed before PCR (data not shown). PCR amplification of genomic viral DNA resulted in the amplification of a 789 bp product because of the presence of a 132 bp intron. (d) Western blot analysis revealed that, compared with controls (time $=0 \mathrm{~h}$ ), Cx43 was decreased in COCs infected with the adenovirus expressing the Cx43 cDNA in the antisense orientation (Ad-asCx43) after $6 \mathrm{~h}$ of infection. Samples of heart and aorta were used as positive controls. Cx43 was detected as three bands of 43-45 kDa in heart and one band in aorta. Lanes of heart and aorta samples were loaded with $40 \mu \mathrm{g}$ total protein. Lanes of COC samples were loaded with $50 \mu \mathrm{g}$ total protein.

$24 \mathrm{~h}$ in this defined medium, as they could be fertilized efficiently with spermatozoa (Chanson et al., 2001).

Long chain alcohols (1-heptanol or octanol), which block gap junction channels in a rapid manner (Chanson et al., 1989), were used to interfere with intercellular communication. Heptanol reduces gap junctional coupling between cumulus cells and oocytes (Fagbohun and Downs, 1991) and can be used to inhibit the function of cumulus cells during oocyte maturation without having to remove them. In the present study, the involvement of intercellular communication mediated by gap junction channels in oocyte maturation of in vitro cultured bovine COCs was investigated. In the presence of these alkanols, only $29 \%$ of the COCs reached metaphase II and removal of the uncoupling agent was associated with restoration of oocyte maturation. These data indicate that gap junction-mediated communication between cumulus cells plays a crucial role in maturation of bovine oocytes. The same uncoupling agents have been used in Xenopus laevis to examine the role of follicle cell-oocyte gap junction coupling (Patino and Purkiss, 1993); these data indicate that gap junctional coupling between follicle cells and oocytes is required for maturational steroid signalling in amphibian ovaries. Using heptanol, Coskun and Lin (1994) showed that transforming 


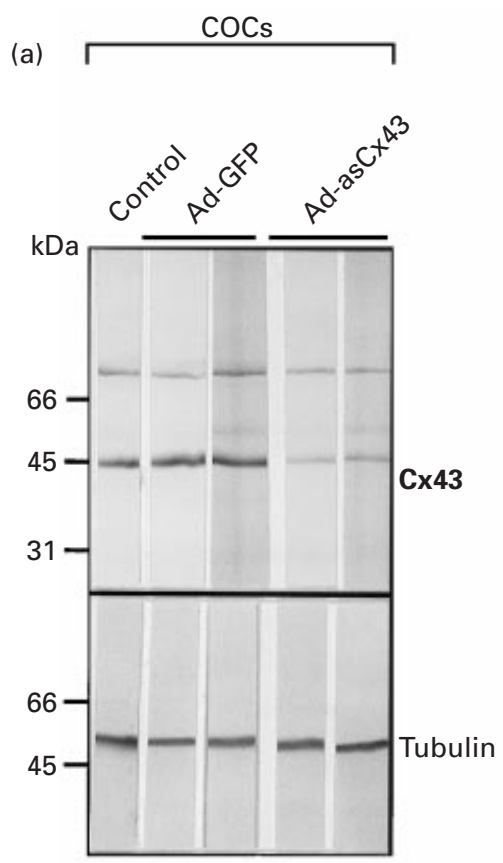

(b)

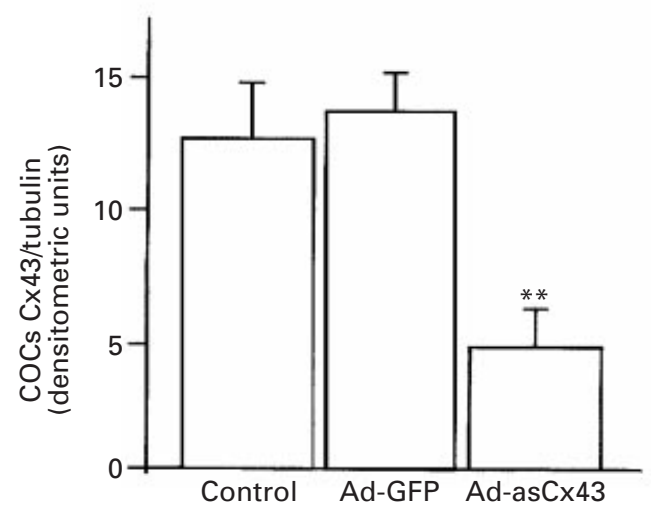

Fig. 3. Decreased connexin $43(\mathrm{C} \times 43)$ content in bovine cumulus-oocyte complexes (COCs) infected with Ad-asCx43. (a) Western blot analysis of $\mathrm{Cx} 43$ revealed that the content of this protein (43 kDa band) was lower in the COCs infected with the adenovirus expressing the $\mathrm{C} \times 43 \mathrm{cDNA}$ in the antisense orientation (Ad-asCx43) than in COCs infected with Ad-GFP (green fluorescence protein). This difference was not observed with $\alpha$ tubulin $(50 \mathrm{kDa})$, indicating that the same amount of total proteins was loaded $(50 \mu \mathrm{g})$. (b) Quantitative evaluation of four immunoblots revealed that $\mathrm{Cx} 43$ content was reduced by $65 \%$ in samples of COCs infected with $\mathrm{Ad}-\mathrm{asC} \times 43$. **Significantly different from control $(P<0.01)$.

growth factor $\alpha$ (TGF- $\alpha$ ) induced signalling from cumulus cells to oocytes via gap junctions. Recently, using the same blocking agent, Mori et al. (2000) demonstrated that gap junctions play an important role in regulating the cytoplasmic factors responsible for the removal of sperm nuclear envelopes and glutathione inflow from cumulus cells. Downs (1995) demonstrated further that gap junctions are involved in the mediation of both stimulatory and inhibitory signals from the cumulus cells, due to the
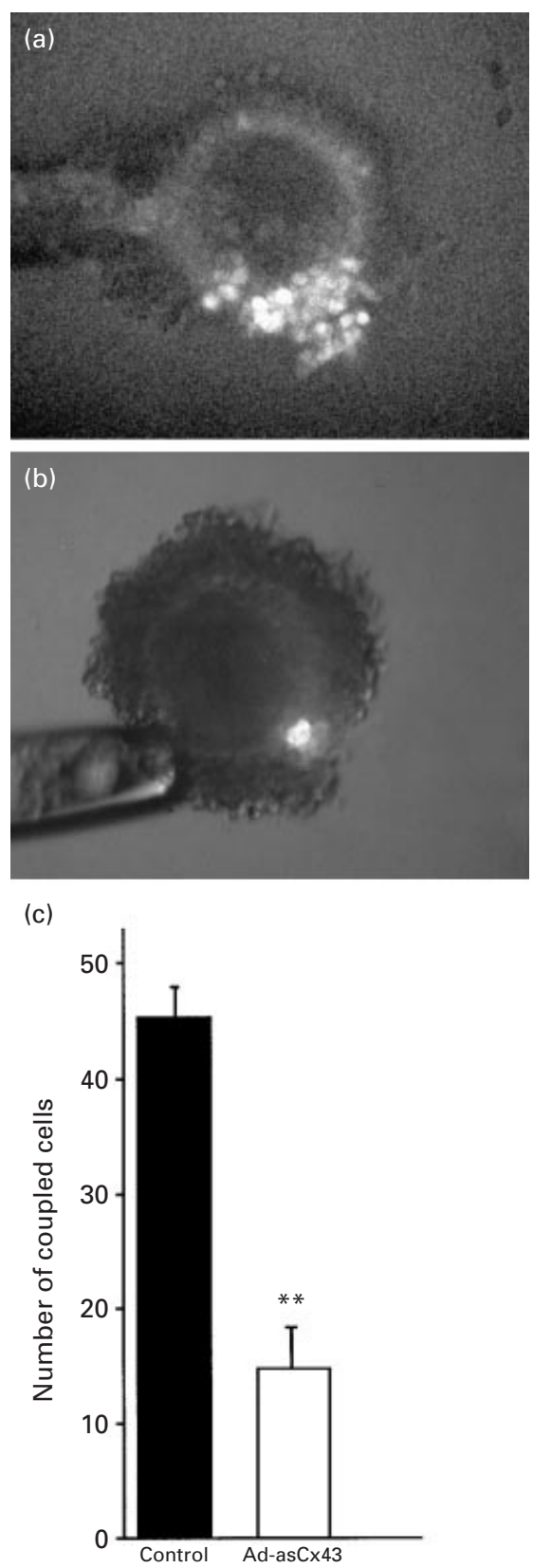

Fig. 4. Extent of dye coupling in bovine cumulus-oocyte complexes (COCs) expressing antisense connexin 43 (Cx43) RNA. Fluorescent view of (a) a control COC or (b) a COC infected with Ad-asCx43 after injection of Lucifer yellow at $24 \mathrm{~h}$ after infection. (c) The extent of dye coupling within cumulus cells indicates a $65 \%$ reduction $(* * P<0.01)$ in the number of Lucifer yellow-labelled cells within each COC infected with Ad-asCx43. Cell-to-cell coupling between Ad-asCx43-infected cells was significantly reduced (15 \pm 2$)$ compared with control uninfected cells $(44 \pm 2)$. Values of the extent of dye diffusion are mean $\pm \operatorname{SEM}(n=27$ for control and $n=21$ for infected COCs); results of seven independent experiments.

influence of glucose and ATP concentrations within mouse COCs.

de Loos et al. (1994) proposed that, in bovine oocytes, mural granulosa cells generate a meiosis-arresting substance 


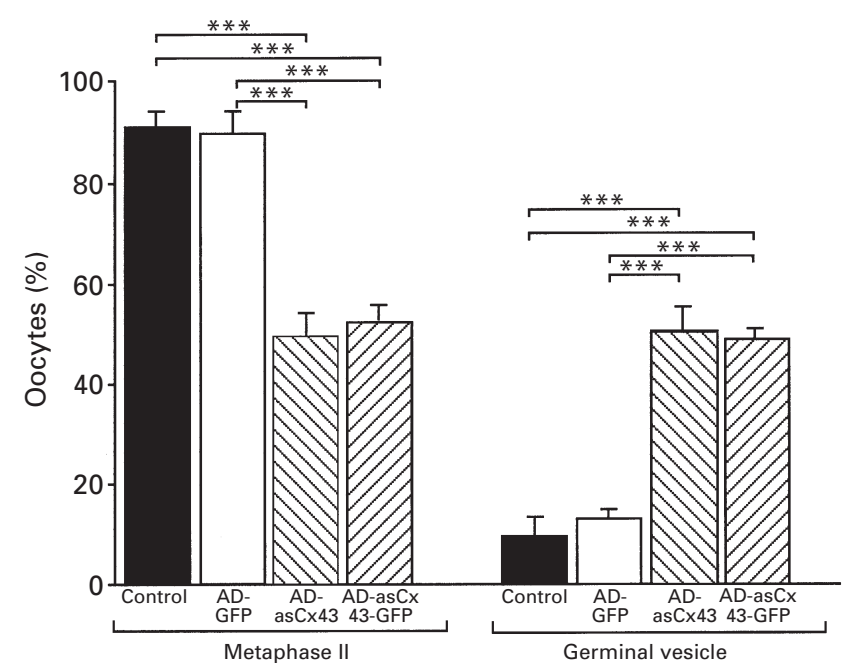

Fig. 5. Decreased maturation of bovine cumulus-oocyte complexes (COCs) infected with $\mathrm{Ad}$-asCx43. The incidence of germinal vesicle breakdown of oocytes infected or not infected with adenoviruses was measured. After $24 \mathrm{~h}$ in culture, $91 \%$ of oocytes from control COCs matured to the metaphase II stage $(\boldsymbol{\square} ; n=67$ in total). In contrast, only 48\% ( $\otimes ; n=94$ in total) and 51\% ( $\square ; n=93$ in total) of oocytes present in COCs infected with $\mathrm{Ad}$-asCx43 (adenovirus and antisense connexin 43) or Ad-asCx43-GFP (green fluorescent protein), respectively, underwent germinal vesicle breakdown. Furthermore, $89 \%$ ( $\square ; n=96$ in total) of the oocytes from COCs infected with Ad-GFP were recovered in the metaphase II stage, indicating that the virus alone has no cytotoxic effect on meiotic maturation of oocytes. Only one oocyte in each condition tested was found at an intermediate stage (data not shown). Data are mean $\pm \operatorname{SEM}\left(n=8\right.$ experiments). ${ }^{* * *} P<0.001$.

and transport it to the oocyte through gap junctions. Completion of meiosis can be induced by separating oocytes from cumulus cells (Edwards, 1965; Racowsky and Baldwin, 1989). In rodents, gap junctional communication could maintain oocyte arrest in the first meiotic prophase by delivering inhibitory signals, such as CAMP, from the cumulus cells (Sandberg et al., 1992; Chesnel et al., 1994). These studies indicate that gap junction communication maintains oocytes that are arrested in the first meiotic prophase. However, if this model is correct, competent oocytes lacking junctional communication with cumulus cells would be expected to undergo premature meiotic resumption. Fagbohun and Downs (1991) demonstrated that gap junctional coupling between cumulus cells and oocytes is necessary to mediate the actions of concanavalin $\mathrm{A}$ and $\mathrm{FSH}$, which induce meiotic resumption in mice; other studies have shown that meiotic resumption precedes loss of gap junctional communication. Metabolic coupling assays performed in several different species have shown that GVBD occurs before any detectable decrease in the transport of small molecules (Schultz et al., 1983; Motlik et al., 1986; Hyttel, 1987; Eppig and Downs, 1988; Mattioli et al., 1988; de Loos et al., 1991; Laurincik et al., 1992), thereby indicating that junctions between COCs remain functional until metaphase II.
The junctions coupling the cumulus cells with the oocytes are composed partly of Cx37 (Simon et al., 1997); female mice lacking Cx37 are infertile because ovulation does not occur (Simon et al., 1997). Only a small percentage of oocytes mature sufficiently to resume meiosis. As oocytes in female mice lacking Cx37 never acquire meiotic competence, these follicles in vivo do not permit us to test this model (Goodenough et al., 1999). These in vivo data indicate that growth-promoting signals from follicular cells, necessary for oocyte meiotic maturation, permeate through gap junctions (White and Paul, 1999).

Juneja et al. (1999) showed that the gonads of fetal and neonatal mice lacking Cx43 are unusually small owing to a deficiency of germ cells. In addition, postnatal folliculogenesis is impaired in ovaries lacking Cx43 (Juneja et al., 1999). These results imply that Cx43 is required for both germline development and the early stages of folliculogenesis in the ovaries. In cows, Cx43 is present only in granulosa cells and on the borders between granulosa cells and oocytes (Johnson et al., 1999) and concentrations increase in healthy developing antral follicles. Cx32 is present only between granulosa cells of atretic and small antral follicles, whereas Cx26 is expressed in the oocytes of primordial and primary or secondary follicles, and in the granulosa of healthy antral follicles (Johnson et al., 1999). In bovine ovaries, Cx37 is localized in bovine ovarian follicles and is present predominantly at preantral stages (Nuttinck et al., 2000). Cx37 is detected in both oocyte and granulosa cell compartments. Cx37 expression decreases significantly at the onset of antral cavity formation, whereas Cx43 is expressed weakly in preantral follicles. These data indicate that $\mathrm{C} \times 37$ and $\mathrm{C} \times 43$ expression patterns are regulated differentially throughout folliculogenesis. This complex pattern of gap junction expression indicates that gap junctional coupling plays an indispensable role in regulating development and regression of follicles and may reflect specific physiological roles for each connexin.

An adenovirus gene transfer approach was used to decrease Cx43 expression specifically in bovine cumulus cells to study the involvement of $\mathrm{Cx} 43$ further. By reducing the expression of Cx43, as demonstrated by western blot analysis and injections of Lucifer yellow, the incidence of maturation was decreased by $50 \%$, demonstrating that specific cellular communications mediated by $\mathrm{C} \times 43$ are critical for meiotic maturation of oocytes. The disruption of cell-to-cell communication between the cumulus cells could participate in triggering the resumption of meiosis by allowing the synergic effect of coupled cumulus cells to signal, via gap junctions, a diffusable factor necessary to elicit proper meiotic maturation of oocytes. The nature of these molecules is still unknown and the use of adenoviruses to decrease $\mathrm{Cx} 43$ expression between the cumulus cells may be useful to characterize those involved in meiotic resumption. Geshi et al. (2000) demonstrated that sodium pyruvate promotes nuclear maturation in bovine cumulus-denuded oocytes and that a continuous presence of cumulus cells during oocyte maturation is important for 
subsequent development of zygotes to the blastocyst stage in cattle. These findings indicate that cumulus cells may metabolize glucose which can be passed to the oocyte, presumably through gap junctions.

In conclusion, the different approaches used in the present study indicate that gap junction-mediated communication between cumulus cells plays a crucial role in maturation of bovine oocytes. A novel strategy was used to inhibit Cx43 expression specifically and decreased Cx43 protein content resulted in significantly lower gap junction communication, as observed by Lucifer yellow staining. The present study is the first in which the major role played by Cx43 in gap junction communication in oocyte maturation has been demonstrated; this connexin appears to be largely responsible for proper gap junction communication and adequate Cx43 expression is important for maturation of bovine oocytes. These data indicate that intercellular communication mediated by gap junctions between cumulus cells is required for proper meiotic maturation of oocytes and that Cx43 plays an important role in this process.

J-A. Haefliger is supported by a career award from the Max Cloëtta Foundation. This work was supported by a grant from the Swiss National Science Foundation (31-56689.99 to J-A. Haefliger) and the Placide Nicod and Octav Botnar Foundations. The authors would like to thank P. Francfort, Veterinarian, and J-F. Deschenaux for their help during collection of the ovaries at the slaughterhouse. The recombinant $\mathrm{LH}$ and FSH were kindly provided by Serono (Geneva).

\section{References}

Beyer EC, Paul DL and Goodenough DA (1987) Connexin43: a protein from rat heart homologous to a gap junction protein from liver Journal of Cell Biology 105 2621-2629

Beyer EC, Kistler J, Paul DL and Goodenough DA (1989) Antisera directed against connexin43 peptides react with a 43-kD protein localized to gap junctions in myocardium and other tissues Journal of Cell Biology 108 595-605

Blondin P and Sirard MA (1995) Oocyte and follicular morphology as determining characteristics for developmental competence in bovine oocytes Molecular Reproduction and Development 41 54-62

Bornslaeger EA and Schultz RM (1985) Regulation of mouse oocyte maturation: effect of elevating cumulus cell cAMP on oocyte cAMP levels Biology of Reproduction 33 698-704

Bruzzone R, White TW and Paul DL (1996) Connections with connexins: the molecular basis of direct intercellular signaling European Journal of Biochemistry 238 1-27

Buccione R, Schroeder AC and Eppig JJ (1990) Interactions between somatic cells and germ cells throughout mammalian oogenesis Biology of Reproduction 43 543-547

Chanson A, Nocera D, Senn A, De Grandi P and Germond M (2001) Development of a well defined medium for the in vitro maturation of immature bovine cumulus-oocyte complexes Journal of Assisted Reproduction and Genetics 18 99-107

Chanson M, Bruzzone R, Bosco D and Meda P (1989) Effects of $n$-alcohols on junctional coupling and amylase secretion of pancreatic acinar cells Journal of Cell Physiology 139 147-156

Chanson M, Fanjul M, Bosco D, Nelles E, Suter S, Willecke $K$ and Meda $P$ (1998) Enhanced secretion of amylase from exocrine pancreas of connexin32-deficient mice Journal of Cell Biology 141 1267-1275

Chesnel F, Wigglesworth K and Eppig JJ (1994) Acquisition of meiotic competence by denuded mouse oocytes: participation of somatic-cell product(s) and cAMP Developmental Biology 161 285-295
Chomczynski P and Sacchi N (1987) Single-step method of RNA isolation by acid guanidinium thiocyanate-phenol-chloroform extraction Analytical Biochemistry 162 156-159

Christ GJ (1995) Modulation of alpha 1-adrenergic contractility in isolated vascular tissues by heptanol: a functional demonstration of the potential importance of intercellular communication to vascular response generation Life Sciences 56 709-721

Coskun S and Lin YC (1994) Effects of transforming growth factors and activin-A on in vitro porcine oocyte maturation Molecular Reproduction and Development 38 153-159

Dekel N (1988) Spatial relationship of follicular cells in the control of meiosis Progress in Clinical and Biological Research 267 87-101

Dekel N and Beers WH (1980) Development of the rat oocyte in vitro: inhibition and induction of maturation in the presence or absence of the cumulus oophorus Developmental Biology 75 247-254

de Loos FA, Kastrop P, Van Maurik P, Van Beneden TH and Kruip TA (1991) Heterologous cell contacts and metabolic coupling in bovine cumulus-oocyte complexes Molecular Reproduction and Development 28 255-259

de Loos FA, Zeinstra E and Bevers MM (1994) Follicular wall maintains meiotic arrest in bovine oocytes cultured in vitro. Molecular Reproduction and Development 39 162-165

Downs SM (1995) The influence of glucose, cumulus cells, and metabolic coupling on ATP levels and meiotic control in the isolated mouse oocyte Developmental Biology 167 502-512

Edwards RG (1965) Maturation in vitro of mouse, sheep, cow, pig, rhesus monkey and human ovarian oocytes Nature 208 349-351

Eppig JJ (1982) The relationship between cumulus cell-oocyte coupling, oocyte meiotic maturation, and cumulus expansion Developmental Biology 89 268-272

Eppig JJ (1996) Coordination of nuclear and cytoplasmic oocyte maturation in eutherian mammals Reproduction, Fertility and Development 8 485-489

Eppig JJ and Downs SM (1988) The role of purines in the maintenance of meiotic arrest in mammalian oocytes Progress in Clinical and Biological Research 267 103-113

Fagbohun CF and Downs SM (1991) Metabolic coupling and ligandstimulated meiotic maturation in the mouse oocyte-cumulus cell complex Biology of Reproduction 45 851-859

Geshi N, Jorgensen B, Scheller HV and Ulvskov P (2000) In vitro biosynthesis of 1,4-beta-galactan attached to rhamnogalacturonan I Planta 210 622-629

Goodenough DA, Goliger JA and Paul DL (1996) Connexins, connexons, and intercellular communication Annual Review of Biochemistry 65 475-502

Goodenough DA, Simon AM and Paul DL (1999) Gap-junction mediated intercellular signalling in health and disease Novartis Foundation Symposium 219 226-235 (Discussion 235-240)

Gougeon A (1996) Regulation of ovarian follicular development in primates: facts and hypotheses Endocrine Reviews 17 121-155

Granot I and Dekel N (1997) Developmental expression and regulation of the gap junction protein and transcript in rat ovaries Molecular Reproduction and Development 47 231-239

Grazul-Bilska AT, Reynolds LP and Redmer DA (1997) Gap junctions in the ovaries Biology of Reproduction 57 947-957

Haefliger JA, Castillo E, Waeber G, Bergonzelli GE, Aubert JF, Sutter E, Nicod P, Waeber B and Meda P (1997) Hypertension increases connexin43 in a tissue-specific manner Circulation 95 1007-1114

Haefliger JA, Meda P, Formenton A, Wiesel P, Zanchi A, Brunner HR, Nicod P and Hayoz D (1999) Aortic connexin43 is decreased during hypertension induced by inhibition of nitric oxide synthase Arteriosclerosis, Thrombosis and Vascular Biology 19 1615-1622

Haefliger JA, Polikar R, Schnyder G, Burdet M, Sutter E, Pexieder T, Nicod P and Meda P (2000) Connexin37 in normal and pathological development of mouse heart and great arteries Developmental Dynamics 218 331-344

Heller DT and Schultz RM (1980) Ribonucleoside metabolism by mouse oocytes: metabolic cooperativity between the fully grown oocyte and cumulus cells Journal of Experimental Zoology 214 355-364 
Hirt B (1967) Selective extraction of polyoma DNA from infected mouse cell cultures Journal of Molecular Biology 26 365-369

Hitt M, Bett A, Prevec L and Graham FL (1998) Construction and propagation of human adenovirus vectors. In Construction and Propagation of Human Adenovirus Vectors Volume 1 pp 500-512.

Hyttel P (1987) Bovine cumulus-oocyte disconnection in vitro. Anatomy and Embryology 176 41-44

Johnson ML, Redmer DA, Reynolds LP and Grazul-Bilska AT (1999) Expression of gap junctional proteins connexin 43, 32, and 26 throughout follicular development and atresia in cows Endocrine 10 43-51

Juneja SC, Barr KJ, Enders GC and Kidder GM (1999) Defects in the germ line and gonads of mice lacking connexin43 Biology of Reproduction 60 1263-1270

Kumar NM and Gilula NB (1996) The gap junction communication channel Cel/ 84 381-388

Largo C, Tombaugh GC, Aitken PG, Herreras O and Somjen GG (1997) Heptanol but not fluoroacetate prevents the propagation of spreading depression in rat hippocampal slices Journal of Neurophysiology 77 9-16

Larsen WJ, Wert SE and Brunner GD (1986) A dramatic loss of cumulus cell gap junctions is correlated with germinal vesicle breakdown in rat oocytes Developmental Biology 113 517-521

Laurincik J, Kroslak P, Hyttel P, Pivko J and Sirotkin AV (1992) Bovine cumulus expansion and corona-oocyte disconnection during culture in vitro. Reproduction, Nutrition and Development 32 151-161

Lenhart JA, Downey BR and Bagnell CA (1998) Connexin 43 gap junction protein expression during follicular development in the porcine ovary Biology of Reproduction 58 583-590

Mattioli M, Galeati G, Bacci ML and Seren E (1988) Follicular factors influence oocyte fertilizability by modulating the intercellular cooperation between cumulus cells and oocyte Gamete Research 21 223-232

Mori T, Amano T and Shimizu H (2000) Roles of gap junctional communication of cumulus cells in cytoplasmic maturation of porcine oocytes cultured in vitro. Biology of Reproduction 62 913-919

Motlik J, Fulka J and Flechon JE (1986) Changes in intercellular coupling between pig oocytes and cumulus cells during maturation in vivo and in vitro. Journal of Reproduction and Fertility 76 31-37

Nuttinck F, Peynot N, Humblot P, Massip A, Dessy F and Flechon JE (2000) Comparative immunohistochemical distribution of connexin 37 and connexin 43 throughout folliculogenesis in the bovine ovary Molecular Reproduction and Development 57 60-66

Patino R and Purkiss RT (1993) Inhibitory effects of $n$-alkanols on the hormonal induction of maturation in follicle-enclosed Xenopus oocytes: implications for gap junctional transport of maturation-inducing steroid General and Comparative Endocrinology 91 189-198

Racowsky C and Baldwin KV (1989) In vitro and in vivo studies reveal that hamster oocyte meiotic arrest is maintained only transiently by follicular fluid, but persistently by membrana/cumulus granulosa cell contact Developmental Biology 134 297-306

Richard FJ and Sirard MA (1996a) Effects of follicular cells on oocyte maturation. I: Effects of follicular hemisections on bovine oocyte maturation in vitro. Biology of Reproduction 54 16-21

Richard FJ and Sirard MA (1996b) Effects of follicular cells on oocyte maturation. II: Theca cell inhibition of bovine oocyte maturation in vitro. Biology of Reproduction 54 22-28

Richard FJ, Fortier MA and Sirard MA (1997) Role of the cyclic adenosine monophosphate-dependent protein kinase in the control of meiotic resumption in bovine oocytes cultured with thecal cell monolayers Biology of Reproduction 56 1363-1369

Sandberg K, Ji H, lida T and Catt KJ (1992) Intercellular communication between follicular angiotensin receptors and Xenopus laevis oocytes: medication by an inositol 1,4,5-trisphosphate-dependent mechanism Journal of Cell Biology 117 157-167

Schaack J, Langer S and Guo X (1995) Efficient selection of recombinant adenoviruses by vectors that express beta-galactosidase Journal of Virology 69 3920-3923

Schultz RM, Montgomery RR, Ward-Bailey PF and Eppig JJ (1983) Regulation of oocyte maturation in the mouse: possible roles of intercellular communication, CAMP, and testosterone Developmental Biology 95 294-304

Simon AM, Goodenough DA, Li E and Paul DL (1997) Female infertility in mice lacking connexin 37 Nature 385 525-529

Sirard MA and Bilodeau S (1990a) Effects of granulosa cell co-culture on in vitro meiotic resumption of bovine oocytes Journal of Reproduction and Fertility 89 459-465

Sirard MA and Bilodeau S (1990b) Granulosa cells inhibit the resumption of meiosis in bovine oocytes in vitro. Biology of Reproduction 43 777-783

Sutovsky P, Flechon JE, Flechon B, Motlik J, Peynot N, Chesne P and Heyman Y (1993) Dynamic changes of gap junctions and cytoskeleton during in vitro culture of cattle oocyte-cumulus complexes Biology of Reproduction 49 1277-1287

Tucker KE, Hurst BS, Guadagnoli S, Dymecki C, Mendelsberg B, Awoniyi CA and Schlaff WD (1996) Evaluation of synthetic serum substitute versus serum as protein supplementation for mouse and human embryo culture Journal of Assisted Reproduction and Genetics 13 32-37

Venance L, Premont J, Glowinski J and Giaume C (1998) Gap junctional communication and pharmacological heterogeneity in astrocytes cultured from the rat striatum Journal of Physiology 510 429-440

Weathersbee PS, Pool TB and Ord T (1995) Synthetic serum substitute (SSS): a globulin-enriched protein supplement for human embryo culture Journal of Assisted Reproduction and Genetics 12 354-360

White TW and Paul DL (1999) Genetic diseases and gene knockouts reveal diverse connexin functions Annual Review of Physiology 61 283-310

Received 24 January 2001.

First decision 16 March 2001.

Final version received 8 June 2001.

Accepted 19 June 2001. 